\title{
ACE-D/I SNP polymorphism in Iraqi patients with chronic renal failure in Thi-Qar province
}

\author{
Eman J. Ali ${ }^{1}$, Hind M. Mousa ${ }^{2}$ \\ ${ }^{1}$ Al-Shattra Hospital, Thi-Qar, Ministry of Health, Iraq. \\ ${ }^{2}$ Pathological Analysis Department, Faculty of Science, University of Thi-Qar, Iraq.
}

\begin{abstract}
Precise characterization of clinical phenotypes and revelation of genetic markers for the predisposing to have renal maladies or alter its course has been bothersome and exhausting. However, some genetic variants have been linked to kidney disorders. This study involved 120 subjects (70 hemodialysis-treated patients with chronic renal failure and 50 healthy subjects as control). Serum biochemical parameters creatinine and urea were detected as diagnostic markers to renal functions. Sixty subjects (44 patients \& 16 control) were genotyped for polymorphism of the enzyme gene conversion of angiotensin. The distribution of genotype and allele frequencies for angiotensin- converting enzyme - Deletion / Insertion single nucleotide polymorphisms has been evaluated in both groups. The levels of biochemical parameters creatinine, and urea in renal failure patients increased significantly when compared with healthy .The angiotensin-converting enzyme genotypes distribution between subjects groups in Thi- Qar indicated that the percentage of DD genotype was found to be high in the group of 23 patients (52.3\%), followed by ID $16(36.3 \%)$ and II genotype $5(11.4 \%)$. As, the genetic pattern in the control group showed that the genotype DD and ID patterns had the same percentage of $37.3 \%$, followed by genotype II, $25 \%$. Also, there is an increase of D- allele frequencies in the group of patients equivalent with healthy controls. The high frequency of angiotensin-converting enzyme DD genotype and D allele compared to control in chronic renal failure patients can be a significant factor in the development of renal failure..
\end{abstract}

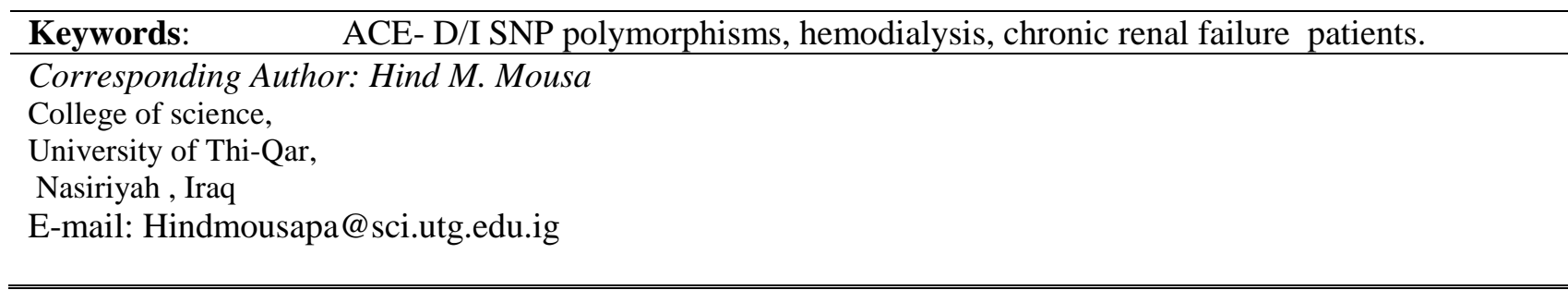

\section{1- Introduction}

Genetic factor plays an important role in chronic kidney disease progression and end-stage kidney disease (ESRD) development [1]. As noted, the rate of long-term renal function loss presents a great contrast between individuals, even among those who have the same type of kidney disease[2] . Recently developments in new molecular genetic techniques have presented visions in the role of genetic change in kidney disorders with the possibility of developing the path of kidney disease and benefit from precautionary treatment [2]. Genetic factors can affect the phenotype of the renal disease in several ways: the vulnerability to renal disease, the normal course of the disease, and the treatment reaction. To order to understand the role of genetic factors to renal disorder, it is important to recognize between these possible mechanisms [3]. Angiotensin-converting enzyme (ACE) genotype is perhaps one of the risk factors for both the progression and advancement of renal disorders or may indicate genetic propensity to illness [3]. The human ACE quality is situated on chromosome 17 (17q23) contains 25 introns and 26 exons [3, 4]. ACE gene has in excess of 160 gene polymorphisms; Single nucleotide polymorphism (SNP) is the vast majority. In this gene, the SNP includes either a deletion (D) allele or an insertion (1) allele in a DNA sequence of 287-basepair in intron 16 of the ACE gene coding structuring three probable genotypes: DD, 11 or ID [4] . Many studies were carried out to determine the association between ACE polymorphism and renal failure progression [4-6] . 
The results of one studies conducted on Lebanese individuals indicated that allele D can be considered a factor eligible for progression of both DN and DN to ESRD in Lebanese who suffer from T2DM [7]. Also, in Iran Rahimi et al [8] indicated that ACE D allele increases the risk of hypertension in ESRD patients [8] .

Recently, the results of Al-Radeef et al. in Baghdad, showed that the angiotensin-converting enzyme genetic polymorphism had a significant impact on serum erythropoietin rates and had no significant effect on hemoglobin levels in Iraqi hemodialysis patients [9] . Thus, the D allele is reported to be either indifferent, or associated with the worst renal diagnosis, the evidence seems to favor the role of the allele in the development of renal function loss, although not in the entire population and not at all.

Therefore, this study was designed to be one of the studies that highlight chronic renal failure in Thi Qar province, by studying the genetic profile of one gene associated with genetic predisposition to the development of renal failure by evaluating the role of ACE I/D SNP polymorphism for patients with healthy people and renal failure as a diagnostic sign of early disease detection.

\section{Material and methods}

This study was conducted at Immunological and Molecular Laboratory University of Thi-Qar-college of science in pathological analysis department, on a group of patients at AL-Hussein Tea ching Hospital in T hi- Q ar, and the control group at the period between October 2018 to May 2019. It included (120 subjects (50 control range of age from 25-60 and 70 patients with chronic renal failure ranged from ( 25-70). Patients (before the dialysis session) collected three milliliters of venous blood samples and were healthy. Serums have been isolated from two $\mathrm{ml}$ of centrifuged blood samples and the specific serum is used to test biochemical parameters (creatinine and urea), while the remaining one $\mathrm{ml}$ has been stored in EDTA vials of genomic DNA extraction. According to the Promega protocol of the manufacturer, genomic DNA extracted from blood samples using the RediaperTM Blood gDNA Miniprep System (Promega, USA) provides a quick, simple technique for mammalian blood preparation of purified and intact DNA, the quality and concentration of extracted DNA were analyzed by using Nano drop spectrophotometer 1000 - Taiwan that assessed the consecration at (ng/ul) and evaluated the quality (purity) of DNA by reading the absorbance at $(260 / 280 \mathrm{~nm})$ and the DNA bands have been seen by electrophoresis of the agarose gel.

The polymorphism of the ACE gene was detected using polymerase chain reaction (PCR) using the technique defined by Al-Radeef et al. [9]. The SNP in ACE gene involves two allelic forms (D and I ), corresponding to the deletion or the insertion that forms three probable genotypes: DD, II or ID.

The ACE gene coding sequence has been enhanced from genomic DNA using sequence specific oligonucleotide primers: $\quad$ Forward: $5^{\prime} \mathrm{C}$ TG GAG ACC ACT CCC ATCCTTTCT 3, Reverse: $\quad 5$ 'GATGTG GCCATCACA TTCGTCAGAT3.' The reaction mix and PCR conditions are given in (Table-1) and (Table -2).

Table 1. The PCR reaction mix $(20 \mu 1)$ for ACE gene.

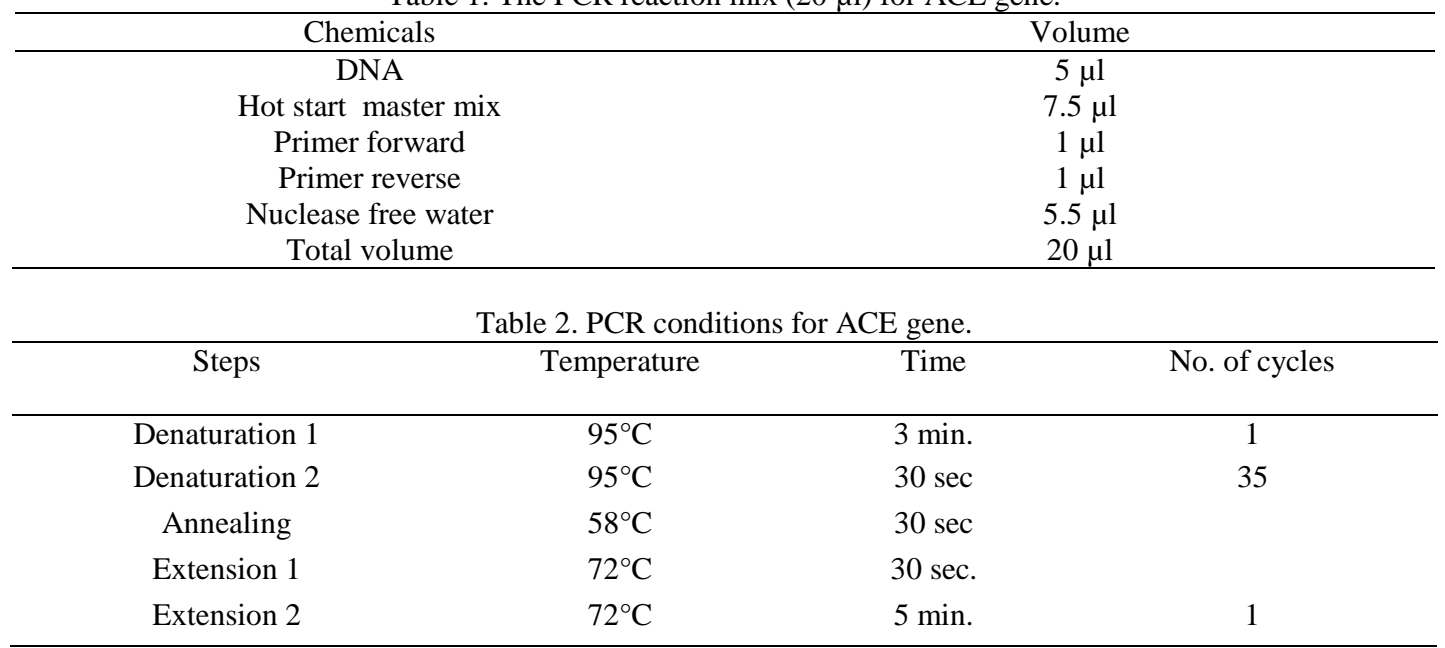

The samples were subjected to electrophoresis of $1.5 \%$ agarose gel electrophoresis at $72 \mathrm{~V}$ for 60 min and visualized at room temperature under UV light after Nancy DNA-520 (Sigma-UK) staining (10uL/50mL) to characteristic fragment patterns of ACE gene locus PCR products (490 bp for insertion and $190 \mathrm{bp}$ for deletion products. 
Statistical calculations were made using version 22 of the SPSS program. For each variable the values are presented as meani SD; in all measurements, $\mathrm{p}$ value 0.05 has been considered statistically significant. Odds ratio and relative risk were used to quantify the strength of the connotation between genotypes alleles of angiotensin-converting enzyme gene and the risk of development CRF in Iraqi patients.

\section{Results}

Table (3) showed the serum urea and creatinine level in the group of patients compared to the control.

Table 3. Levels of renal function tests in control and patients groups

\begin{tabular}{|c|c|c|c|}
\hline Parameters & $\begin{array}{c}\text { Control } \\
(\text { Mean } \pm \text { SD }) \\
50\end{array}$ & $\begin{array}{c}\text { Patient } \\
(\text { Mean } \pm \text { SD) } \\
70\end{array}$ & Lsd \\
\hline Urea( mg/dl) & $29.12 \pm 6.21^{b}$ & $71.82 \pm 15.01^{\mathrm{a}}$ & 3.22 \\
\hline Creatinine ( mg/dl) & $1.02 \pm 0.23^{b}$ & $5.33 \pm 1.03^{\mathrm{a}}$ & 0.20 \\
\hline \multirow[t]{2}{*}{ Parameters } & $\begin{array}{c}\text { Control } \\
(\text { Mean } \pm \text { SD) }\end{array}$ & $\begin{array}{c}\text { Patient } \\
(\text { Mean } \pm \text { SD) }\end{array}$ & \multirow[t]{2}{*}{ Lsd } \\
\hline & 50 & 70 & \\
\hline Urea( mg/dl) & $29.12 \pm 6.21^{b}$ & $71.82 \pm 15.01^{\mathrm{a}}$ & 3.22 \\
\hline Creatinine ( $\mathrm{mg} / \mathrm{dl})$ & $1.02 \pm 0.23^{\mathrm{b}}$ & $5.33 \pm 1.03^{\mathrm{a}}$ & 0.20 \\
\hline
\end{tabular}

\section{Angiotensin-Converting Enzyme polymorphism:}

The present study is the first study, investigating associate between ACE polymorphism genotypes and CRF in Iraqi patients of Thi-Qar as far as we know.

\section{Evaluate the concentration and purity of Extracted DNA:}

Genomic DNA in this study, has been isolated from patients' blood and healthy control groups, all samples yielded intact genomic DNA as shown in (Figure 1). The results of DNA isolation showed that there are 60 samples of good quality and absorption when measured by nano spectrometry (Nanodrob). The concentration of DNA ranged from ( $21.3-118.1 \mathrm{ng} / \mathrm{ul})$ with mean of $50.8 \mathrm{ng} / \mathrm{pl}$, the purity of DNA ranged from (1.65-1 .9) with a mean of 1.77 as indicated in (Figure 2 ), DNA concentration and purity higher than that of human genomic DNA isolated by Hamad [10] , the results demonstrate the efficiency of the methods and material that provided by bromega extraction kit comparing to extraction method or other Kit that used by [10] .

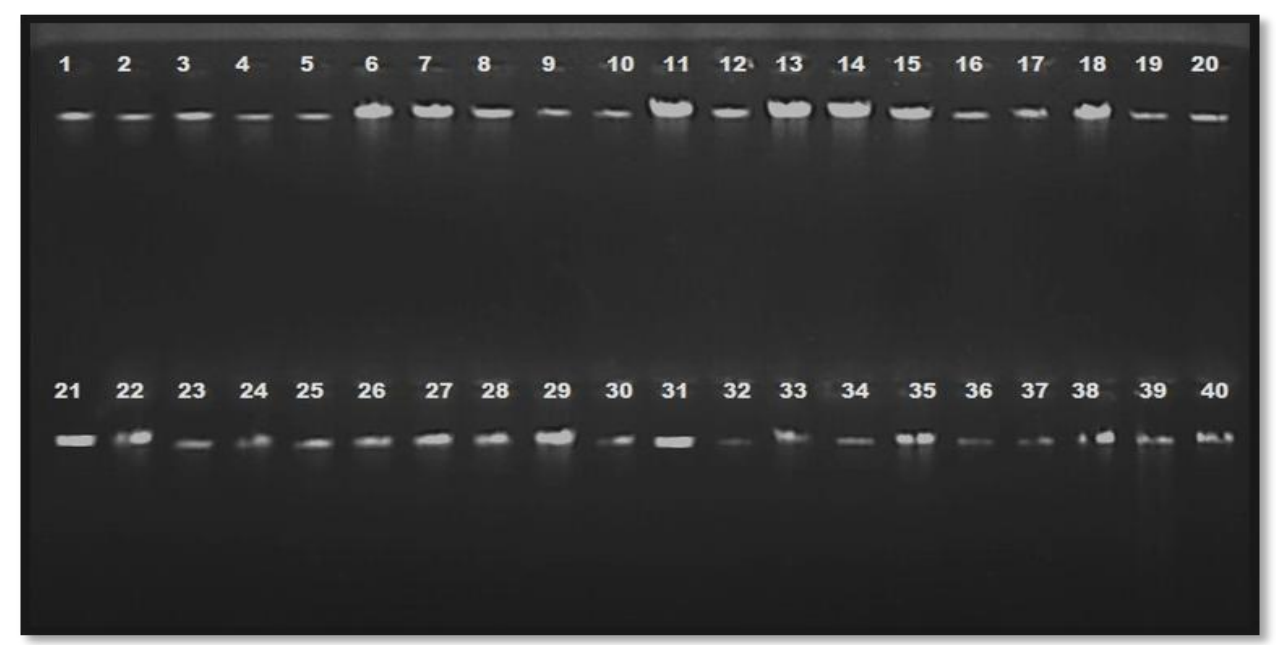

Figure 1. Purity of genomic DNA bands of 40 samples at $0.8 \%$ agarose gel at 80 voltage . 


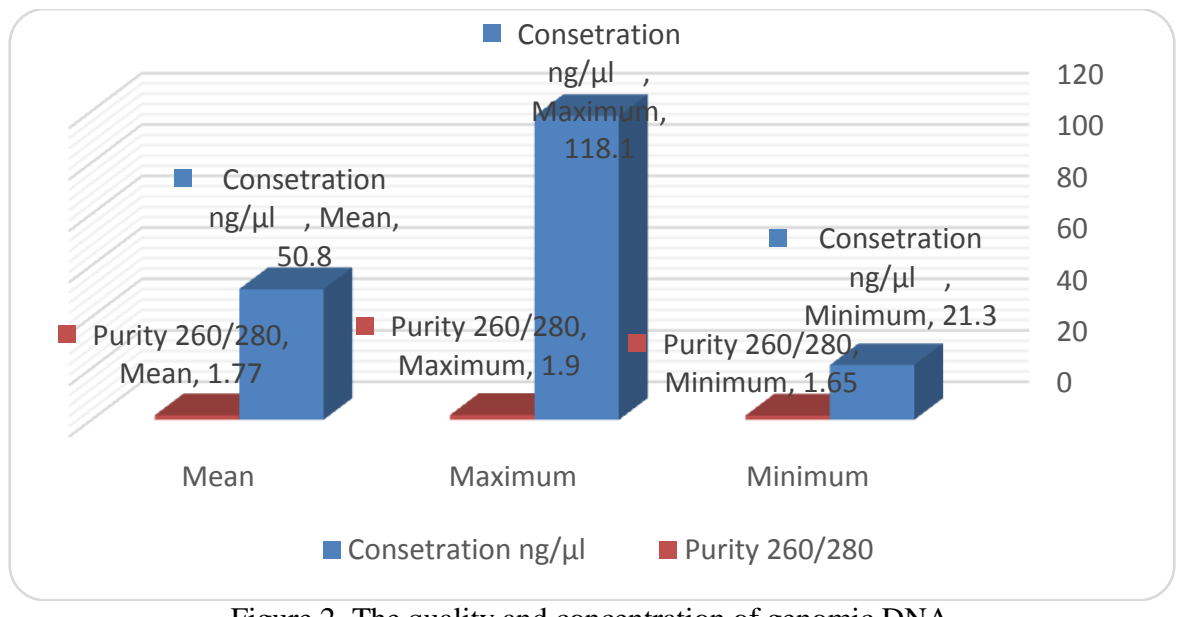

Figure 2. The quality and concentration of genomic DNA

After that the DNA samples used to prepare PCR product for ACE gene. The results of the PCR analysis presented that the presence of a single $190 \mathrm{bp}$ PCR material established the homozygous individuals for the deletion allele D (DD genotype). Then, The presence of a single $490 \mathrm{bp}$ PCR product was described as homozygous for I allele (II genotype as a wild type ), while the existence of 190 and $490 \mathrm{bp} \mathrm{PCR} \mathrm{products}$ were reported as heterozygous individuals (ID genotype) as shown in (Figure 3).

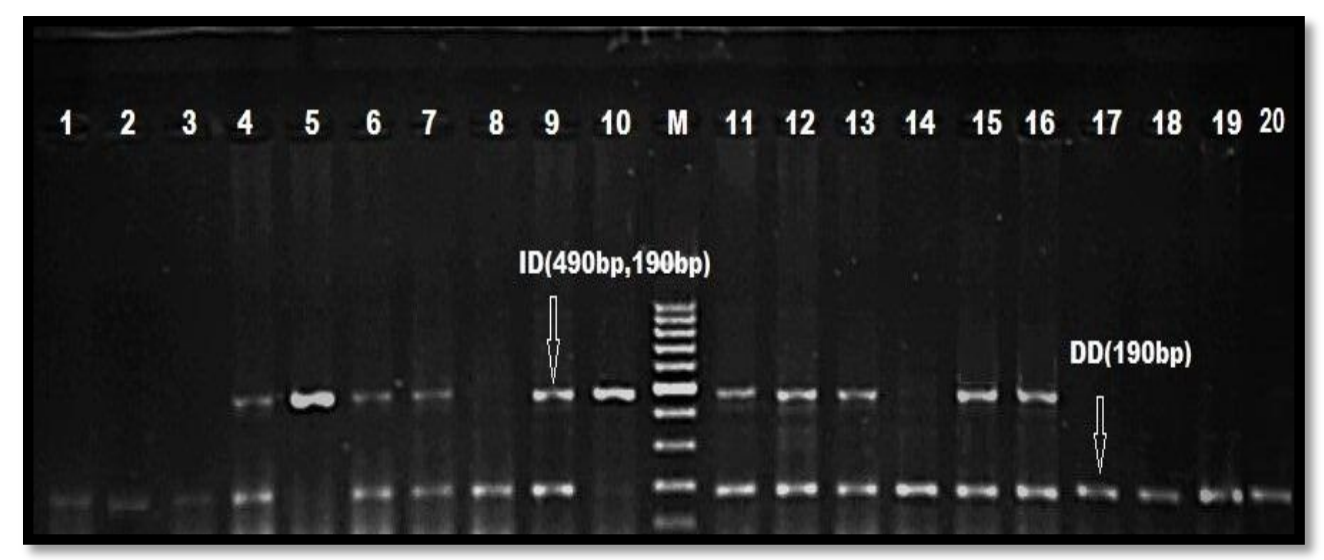

Figure 3. ACE gene I/D polymorphisms on $1.5 \%$ agarose gel at 72 voltage for one hour. 1, M: DNA ladder (100 bp), Individuals were homozygous for the D allele (DD ; 190 bp lane 1,2,3,8,14,17, and 18-20). Individuals were homozygous for the I allele (II genotypes ; $490 \mathrm{bp}$, lane 5, and 10). Heterozygous individuals for the ID genotype (190 bp, and $490 \mathrm{bp}$, lane 4,6,7,9,11-13, 15, and 16 ).

The distribution of ACE polymorphisms by genotype and allele frequencies are presented in (Table 4) and (Table 5).

Table 4.Genotypes distribution of ACE polymorphism among patients and healthy control . S: Significant, HS : High significant , NS: Non significant.

\begin{tabular}{|c|c|c|c|c|c|c|}
\hline ACE & $\begin{array}{l}\text { Control } \\
\text { NO.16 }\end{array}$ & $\begin{array}{l}\text { CKD } \\
\text { NO.44 }\end{array}$ & $\mathrm{P}$ value & Odds Ratio & $\begin{array}{c}\text { Relative Risk fo } \\
\text { control }\end{array}$ & $\begin{array}{c}\text { Relative Risk for } \\
\text { patient }\end{array}$ \\
\hline DD & $6 / 16(37.5 \%)$ & $23 / 44(52.3 \%)$ & $0.002^{\mathrm{HS}}$ & 1.825 & 0.764 & 1.394 \\
\hline II & $4 / 16(25 \%)$ & $5 / 44(11.4 \%)$ & $0.033^{\mathrm{S}}$ & 0.385 & 1.182 & 0.455 \\
\hline ID & $6 / 16(37.5 \%)$ & $16 / 44(36.3 \%)$ & $0.793^{\mathrm{NS}}$ & 0.952 & 1.018 & 0.970 \\
\hline $\begin{array}{l}\text { Total } \\
\text { pvalue } \\
\mathrm{X}^{2}\end{array}$ & $\begin{array}{l}16 / 60(26.7 \%) \\
\mathrm{P}>0.05 \mathrm{NS} \\
3.34\end{array}$ & $\begin{array}{l}44 / 60(73.3 \%) \\
1.01 \mathrm{H} \\
1038\end{array}$ & HS & $\ldots \ldots$ & $\ldots \ldots$ & $\ldots$ \\
\hline
\end{tabular}


Table 5.Alleles frequencies of ACE polymorphisms in CRF patients and healthy control .

\begin{tabular}{lccc}
\hline ACE (allele frequency) & D No(\%) & I No(\%) & Total No(\%) \\
& & & $88(100 \%)$ \\
CRF patients & $62(70.5 \%)$ & $26(29.5 \%)$ & $32(100 \%)$ \\
Healthy & $20(62.5 \%)$ & $12(37.5 \%)$ & \\
Cal.X $X^{2}: 0.686$, df: 1 & Tab.X ${ }^{2}: 6.63$, P.value $\leq 0.05$, Odds ratio: 1.43 & \\
\hline
\end{tabular}

\section{Discussion}

Table (3) showed a significant decrease in the serum urea and creatinine level in the group of patients compared to the control group ( $\mathrm{p} \leq 0.05)$. This results agree with previous studies [11, 12]. Reduced number of nephrons in the renal failure increases the level of urea and creatinine that occurs because the kidneys lose their ability to get rid of nitrogenous waste from the blood leading to the accumulation of these substances in the blood $[13,14]$.

Comparison of ACE genotype frequencies in patients with CRF and healthy showed that the DD genotype percentage has been discovered to be high in group $23(52.3 \%)$ of patients; subsequently ID $16(36.3 \%)$ and II genotype 5(11.4\%) (Table 4). While, the genetic pattern in the control group showed that the genotype DD and ID patterns had the same percentage of $37.3 \%$, followed by genotype II, $25 \%$. Table (5) shows that, by comparing with healthy controls, there may be an increase in D-allele frequencies in the group of patients. However, there are significant differences between control groups and patients in II genotypes and the frequency of DD, but there are no significant statistical differences between them in the genotype of ID SNP ACE genotypes. These results are in accordance with a few studies, such as the Sabbar's et al [6] study in Iraq, that showed that the DD genotype percentages were identified to be $56 \%$ high in the group of patients, led by

ID 28 percent and II genotype 16 percent. They also indicated significant differences in DD (P value was 0.0019 and odd ratio 2.47 ) between patients and control group, whereas II genotype (P value 0.02 and odd ratio 0.44) did not show a significant difference in the ID genotype (P value $>0.05$ ), according to the results of Ali et al. [15] who stated that the D allele repetition in ESRD patients was higher (42.40\%) than in healthy control patients in Malaysia (31.05\%). Rahimi et al [8], in Iran discovered that the frequencies of ACE genotypes and allles were not statistically different compared to ESRD patients and controls; the latest findings are inconsistent with the current study showing that there is a significant statistical difference between patients and the control group in SNP ACE genotypes (DD and II).

The current study did not match the results of another local study in Baghdad by Al-Radeef et al. [9] showed that most frequent ID genotype followed by DD and II in overall CKD events, with no significant difference between chronic kidney disease and healthy subjects in these genotypes [9] .

This mismatch can be due to a very important reason related by the small size of the studied samples, environmental heterogeneity and natural genetic in different ethnic groups or it might as the result of the method that is used in this study. From the current results described above, we found that the ACE genotype of the form (DD) and, (D) allele was associated with a relative risk (1.394) and odd ratio (1.825) of CRF. Moreover, most of the studies we cited showed that DD allele was mostly associated with patient progression to ESRD despite the percentage of allele frequency.

\section{Conclusions}

The high frequency of ACE DD genotype and D allele compared to control in CRF patients can be a significant factor in the development of renal failure.

\section{References}

[1] G. Li. Genetic Factors for End-Stage Renal Disease . Journal of Integrative Nephrology and Andrology, (2) $2: 46-49,2015$. 
[2] F. G. H. V. D. Kleij. Angiotensin-converting enzyme gene insertion/deletion polymorphism and renal disease. Groningen: s.n. PhD thesis. University of Groningen . University medical center Groningen , 2002 .

[3] T. Manikandan, I. Madar, K. Priyadarshan, K. Shyam, and A. Kumar. Polymorphism of Angiotensin I converting enzyme become an innate property in renal failure. Int J Pharma \& Bio. Sci ,1 (2):1-6,2010.

[4] T. Zhou, S. Yin, and Y. Qin. Association between angiotensin converting enzyme insertion/deletion gene polymorphism and end-stage renal disease susceptibility. J Renin-Angiotensin-Aldosterone System, 1$10,2012$.

[5] K. S. Zayed. Determination of I/D genetic variation of the Angiotensin Converting Enzyme (ACE) gene in Iraqi patients with Renal Failure . Al-Kufa University Journal for Biology ,9 (3): 1-8,2017.

[6] H. R. Sabbar, O. M. Ali, and F. O. Naser. . Polymorphism Pattern of Angiotensin Converting Enzyme (ACE) Gene in the Chronic Renal Failure Patients . J. Pharm. Sci. \& Res.,10(8): 1983-1985,2018.

[7] S. Fawwaz, M. Balbaa, H. Fakhoury, J. Borjac, and R. Fakhoury. Association between angiotensinconverting enzyme insertion/deletion gene polymorphism and end-stage renal disease in lebanese patients with diabetic nephropathy. Saudi J Kidney Dis Transpl, 28(2):325-329,2017.

[8] Z. Rahimi, H. Abdi, M. Tanhapoor, Z. Rahimi, A. Vaisi-Raygani, and H. Nomani. ACE I/D and MMP-7 A-181G variants and the risk of end stage renal disease. Mol Biol Res Commun, 6 (1):41-44,2017.

[9] M.Y. Al-Radeef, H. A. Fawzi, and A. A. Allawi. ACE gene polymorphism and its association with serum erythropoietin and hemoglobin in Iraqi hemodialysis patients. Appl Clin Genet, 1;12:107-112,2019.

[10] B. J. Hamad. High Risk Human Papilloma Virus: Molecular Detection In Breast Cancer Patients At ThiQar Province /Iraq(Ph.D) Thesis, Collage of science .Thi-Qar Univercity, PP: 107,2019.

[11] R. Nisha, K. SR. Srinivasa, M. K. Thanga,and P. Jagatha. Biochemical Evaluation of Creatinine and Urea in Patients with Renal Failure Undergoing Hemodialysis. Journal Clinical Pathology Labrotary Medical, 1 (2): 1-5, 2017.

[12] E. A. Hassan. Biochemical Study in Iraqi Patients with Chronic Renal Failure Therapy by Regular Hemodialysis. Diyalysis Journal For Pure Science, 14(4):1-13,2018.

[13] C. M. Porth. Essentials of Pathology 2nd Ed, Lippincott Williams \& Wilkins, Philadelphia, 559-74, 2007.

[14] W. A. Mehdi, W. Al-Helfee, W. Abd, and A.S. Dawood. Study of Several Antioxidants, Total Acid Phosphatase, Prostatic Acid Phosphatase, Total and Free Prostate-Specific Antigen in Sera of Man with Chronic Kidney Failure. Kerbala Journal of Pharmaceutical Sciences, 4: 155-165,2012.

[15] A. Ali, R. Vasudevan, P. Ismail, C. L. Thiam Seong, and S. Chakravarthi. Analysis of insertion/deletion polymorphisms of the angiotensin converting enzyme gene in Malaysian end-stage renal disease patients. Journal of the Renin-Angiotensin-Aldosterone System,, 16(4), 1337-1343,2015. 